\title{
UNDERSTANDING DESIGN IN NATURE CAN BENEFIT PRODUCT CONCEPTUAL DESIGN
}

\author{
D.E. SANTOS-REYES ${ }^{1} \&$ T. LAWLOR-WRIGHT ${ }^{2}$ \\ ${ }^{1}$ Manufacturing and Systems Group, Industrial Engineering Department, Universidad Tecnológica de la Mixteca, \\ Oaxaca, Mexico. \\ ${ }^{2}$ Extreme Loading and Design Group, School of Mechanical, Aerospace and Civil Engineering, \\ The University of Manchester, Manchester, UK.
}

\begin{abstract}
Product design is a strategic activity in companies due to the intense competition, more sophisticated market needs, and diverse and rapid changes in technology. Effective engineering design can improve quality, reduce costs and lead-time, thereby better satisfying customer needs. The means to reduce cost, time to market and to improve product quality are more complicated. Product performance, quality, aesthetic and reliability, once considered as fundamental factors in developing new products, are now minimum requirements, as markets have grown more demanding for environmentally friendly products. Product designers are required to conceive faster innovative products of high quality at lower cost and environmentally sound in order to maintain competitiveness in today's global market. Over the last few years, a significant number of tools and methods have been developed in order to assist designers in addressing these issues. In line with this trend, this paper explores the following research question: how would nature solve conceptual product design issues? It maps the process of design in nature into the traditional product concept design, resulting in a creative process for conceptual product design. It is hoped that this insight may help designers gain further understanding of a creative product concept design process so that they comply with market needs.

Keywords: conceptual design, constructal theory, creativity, design, evolution.
\end{abstract}

\section{INTRODUCTION}

Product design has been considered by both researchers and practitioners as a strategic activity within a company. This is due to the intense competition with rival products, sophisticated customer needs, and diverse and rapid changes in technology. Engineering design can improve product quality and reduce cost and the time to market [1]. Market needs are better satisfied when approached at the conceptual design stage. The approaches to reduce cost and lead-time and to improve product quality are becoming more sophisticated [2]. Over the last decades, customer demands, government regulations, competing companies and pressure from green organisations for eco-friendly products have stressed the need to address environmental issues at the product design process [3, 4].

Decision-making processes and tools in the design process have changed drastically over the last decade from sequential engineering to concurrent engineering (CE). CE seeks the simultaneous progress of activities required to introduce products to the market place at the right time, cost and quality. In a CE environment, designers make decisions about many product attributes, such as function, structure, shape, material, cost, regulations, and other requirements in a concurrent way [5]. One of the most powerful CE tools for translating customer requirements into technical product requirements is quality function deployment (QFD). It is argued elsewhere [6] that the QFD matrices provide a systematic process for identifying the critical customer attributes and creating a specific link between the voice of the customer and the new product parameters, which are then translated into production requirements. Moreover, customer's emotions and feelings are investigated in order to define the new product features [7]. Another widely used tool is the Pugh concept selection process for evaluating and selecting new concepts [8]. Pugh argues that the concept selection method aims at selecting the least vulnerable concept, which initiates the final detailed design process. Other 
common tools and methods, such as multi-criteria decision making, are used to assist designers in making decisions in the concept development process [9]. The theory of inventive problem solving, developed by Altshuller [10], has become popular in both academia and industry for developing inventive solutions over the last few years. Optimisation tools and methods such as the multiattribute design optimisation, non-linear programming, robust design and soft computing have also been used extensively in the decision-making processes of engineering design. Over the last two decades, engineering design has been a vital activity in order to address the lifecycle environmental impact of products or systems [3,11]. More recently, engineering design principles have been used to approach crime in the design process [12-15]. Similarly, in recent years it seems that engineers have an increased interest in borrowing design concepts from nature [16, 17]. More recently, engineers have approached design in nature from an engineering perspective [18, 19].

In line with this development, it is believed here that an understanding of the process of design in nature can be of benefit in product conceptual design. This paper explores the following research question: how would nature solve conceptual product design problems? It maps the process of design in nature through the concepts of similitude, analogy and isomorphism in order to gain an insight into the creative process of product concept design. In the remaining sections of the paper, the literature review, the insight of the process of design in nature into a creative concept design, and conclusions and further research are described.

\section{DESIGN, CREATIVITY AND EVOLUTION}

\subsection{Product design}

Design is a conscious process by which an idea is transformed into tangible or intangible products [20]. Engineers use this process, including tools and methods, for solving problems, meeting needs, improving situations or creating something new. Improving existing products is normally called incremental innovation, and at the other end of the continuum creating totally new products is known as radical innovation. Innovation is about adding or creating value. For this reason, design is recognised as a creative process. Historically, decision making in the design process has been through trial and error. This approach has been enhanced by methods such as brainstorming [21], morphological analysis [22] and synectics [23] aimed at breaking what is believed to be mental blocks when developing new solutions. More advanced approaches to idea generation emphasise the systematic decomposition and analysis of the design problem [10]. These methods are based on knowledgebased principles and the application of physical and chemical phenomena.

More recently, numerous approaches have been proposed in literature in order to approach product concept design. Liu et al. [24] propose a product concept design that consists of a series of repeated divergent and convergent steps. This approach is similar to the convergent-divergent concept design methodology developed by Pugh [8] aimed at reducing the vulnerability of new concepts. Stone et al. [25] propose a method to approach design for assembly in the conceptual stage of product design. Essentially, it decomposes a product into a hierarchy of functions and defines a modular architecture of the new product. This helps to reduce the number of individual components to the minimum as possible. Yeo et al. [9] explore the practical applications of multi-criteria decisionmaking tools for evaluating and selecting product concepts. In particular, they explore the analytical hierarchy process and the simple additive weighting approach. Other researchers such as Shah et al. [26] have focused on developing metrics to measure the effectiveness of concept design. Although customer complaints arise from poor product performance, very often the approach is concerned primarily with geometry. The abstraction process usually begins, in its analytical phase, with the 
development of an understanding of the physical product. Designers usually analyse malfunctioning physical components. Many tools and methods have been developed for this purpose. These approaches emphasised the development of computer-aided design models, a working prototype having most of the current features, or a non-functional scale model [27-31]. This information serves as various metaphors of the original product and enables discussions that generate simple pictorial sketches or models readily recognisable as the new product.

Despite the difficulties in using automated tools for concept design, researchers have invested significant effort in developing computer tools for this purpose. For example, Gelsey et al. [32] present an automated conceptual design system that has been used in the design of supersonic aircrafts by means of artificial intelligence. Li and Schmidt [33] present a grammar-based tool to assist designers in generating concepts of gear trains during the conceptual design phase of mechanical systems. Tovey and Porter [34] discuss the relevance of sketching in the concept design, as applied to automotive design to generate form lines, crown lines, area lines, shading and colouring that are of vital importance in the concept design process. Zheng et al. [27] propose a virtual reality system that uses human sensory capabilities as input data in order to develop new product models, such as size and shape at the conceptual design phase.

The emphasis is that physical products are the centre of focus and the abstractions of physical products used in discussions and analysis often retain graphic semblances to the original product. This might create a partial perspective of the problem that can dissuade a designer from a broader search of ideas. Clearly, physical product orientation is a good rigorous engineering approach in the detailed design. In the concept generation phase, designers need as much freedom of association with creative thinking as can be evoked for producing creative concepts. From this insight, it is worth asking: How can other disciplines such as evolution in nature assist designers to generate, evaluate and select new product concepts?

\subsection{Creativity, discovery and invention}

According to Simon [35], creativity is the ability to produce something that is both novel (original or unexpected) and appropriate (useful). Creative people use what already exists and change it into something that did not exist before. In other words, creative ideas are often new combinations of old ideas. Because creativity has to do with the production of new ideas, it involves cognition that seems to occur only within a framework of associated motivational, attitudinal and personality traits. The combination of components in a new way generally involves perception of an analogy. For example, Alexander Graham Bell was puzzled that a small membrane in the human ear, the eardrum, could vibrate powerfully enough to move the solid bones which made up the ear's mechanism. The analogy is that a similar membrane could be used to control the flow of an electric current in response to the airwaves made by sound. This insight was the breakthrough that Bell used to invent the telephone.

On the other hand, Barker and Bissell [36] define invention as the process of creation during which a novel idea becomes a novel product. A novel product incorporates distinctive components not known before and not available from competing products. They argue that design is fundamental to invention. It may be safe to declare that an invention is a material application of a discovery. A discovery is a subjective event, and that in its relation to technology it acquires importance only if applied practically. Only then does it acquire objective value. Simon [35] argues that the development of products from discoveries occurs in a complex social and economic environment. While discovery and product development usually address different problems, the psychological processes of problem solving are very similar. It is often suggested in literature that invention is the formulation of a means to fit an end. However, the end usually reveals only by a chance discovery of the means already in 
existence. And this is an extremely slow process [37]. For example, Alexander Fleming discovered that a colony of bacteria was consumed by a mould organism that was contaminating his culture. About ten years later, penicillin was invented and used, accelerated by the powerful motivation of the Second World War.

Similarly, researchers have paid close attention to the theory of creative thinking in order to develop approaches to product concept design. Cavdar and Babalik [38] discuss the development of an information system to approach creative design in the area of machine acoustics. The system intends to assist the designer with knowledge and principles of acoustics, solution libraries and processes of finding alternative solutions. Redelinghuys [39] proposes a method to assess the novelty or value gain in a design. Two types of assessment, namely current and retrospective, are suggested. The current assessment is intended to be useful when selecting design concepts or when the creative performance of competing design teams needs to be compared. The latter involves the analysis of invention gain from the perspective of the historic growth of a value parameter for the selected types of technical systems. Kim and Cochran [40] state that the theory of inventive problem solving (TRIZ), as developed in the former Soviet Union by Altshuller [10], provides a process for finding a comprehensive solution, while the axiomatic design, as developed by Suh [41], facilitates to evaluate solutions or to show inherent causes of problems. On the other hand, Stefik and Smoliar [42] argue that creativity has been exploited very little in the area of artificial intelligence. Creative problem solving involves finding important solutions that other searcher tools miss and the extra search power comes from the ability to transform the search space.

\subsection{Evolution in nature}

It is known that lizards adapt extremely well to elevated temperatures [43], correlation exists between biological diversity of crops, such as maize, and cultural diversity [44], mammals adapt to different environments [45, 46], some larvae reduce their vulnerability to predators through adaptation to their host plant [47] and so on. How did these organisms come to be that way? How did some organisms come to differ from others? Answering questions like these requires a framework of understanding that recognises change through time. This framework is known as evolution. Evolution accounts for the relatedness among organisms, explaining that species are related by descent from common ancestors. Charles Darwin, the father of the theory of evolution, stated: 'it is not the strongest of the species that survives, nor the most intelligent; it is the one that is most adaptable to change'. It is now recognised that the theory of evolution is a creative design process [48]. Nature would select those individuals in a population of organisms best suited to particular ecological niches. Individuals that have heritable features which make them more likely to survive and reproduce in their particular environment will have better chances of passing those characteristics on to their own offspring. Natural selection acting on varying individuals within a population of organisms could account for all of the great variety of organisms. The ultimate source of this variation is the discrete units of hereditary traits that are known as genes. How can this creative process be used to create product concepts?

\subsection{Engineering design in nature}

Significant effort has been devoted by researchers of various disciplines in order to establish the basic principles that account for the self-organisation of animate and inanimate systems. The usual question has been: how do things come to be as they are? How regulated artificial and natural systems are, shall we say. However, many issues in biology can be addressed without evolution. How do birds fly? How can certain plants (vegetation) grow in the desert? Each of these questions has an immediate answer 
involving aerodynamics and the storage and flow of water in plants. The teleological mechanisms of things, such as animate and inanimate systems, can be addressed from engineering viewpoints. Bejan $[49,50]$, the leading proponent of a theory of design in nature from the perspective of engineering, shows that the natural patterns and flow structures recognised as self-organisation and self-optimisation represent geometric forms, such as the round cross section of a blood vessel, the tree-shaped network or the dendritic flow pattern. The theory that governs the generation of flow geometry in natural systems has been named as constructal theory. The principle-based generation of geometric forms or constructal law is defined by Bejan [51] as: 'for a finite-size system to persist in time (to live), it must evolve in such a way that it provides easier access to the imposed currents that flow through it'. The relevance of this theory is that it completes the cycle from nature to engineering and from engineering to nature. According to this theory, plants evolve in order to facilitate ground-air mass transfer [52]. The proponents of this theory have shown that dendritic crystals such as snowflakes are the most effective heat-flow configurations for achieving rapid solidification [53]. On the other hand, this principle was used to explain variations in the morphology of stony corals and bacterial colonies and the design of plant roots [54,55]. The same principle was used in order to explain the configuration generation of the lung [56], the scaling laws of river basins [57] and the macroscopic features (speed, frequencies, forces) of all modes of animal locomotion (flying, running, swimming) [58].

\section{DESIGN IN NATURE AS A CREATIVE CONCEPT DESIGN PROCESS}

Nature has millions of inventions that have survived in the face of continuously changing environments. In order to benefit the most from nature's inventions, it is critical to bridge between the process of design in nature and engineering design. To accomplish this, Fig. 1 shows the process used here in order to map the process of design in nature into the product concept design process. In essence, the mapping process consists, first, of finding a similitude between the design of a natural

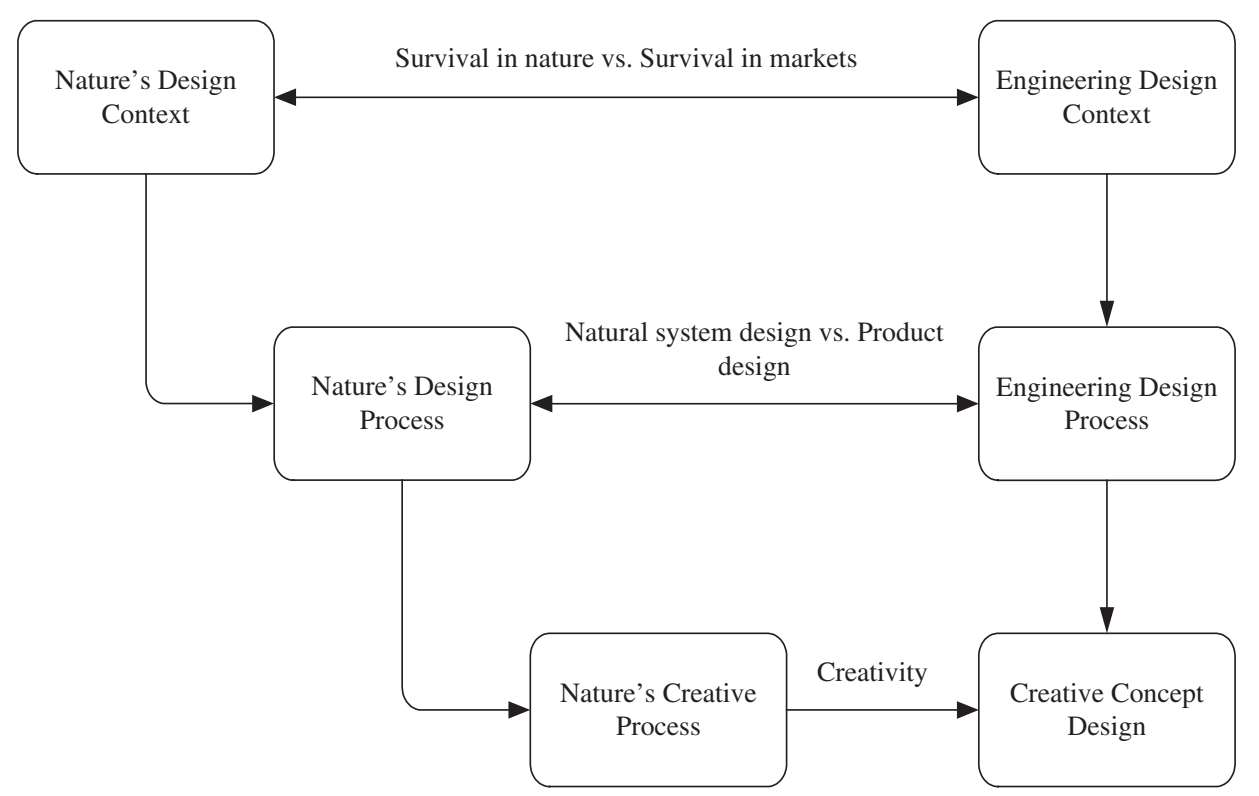

Figure 1: Mapping the evolution process into the product design process. 
system and the engineering design situations. Second, once the insight has been gained from both contexts, an analogy between the two processes is investigated. Finally, the process of design in nature is transformed, as a one-to-one transformation, into a creative product concept design.

\subsection{Survival in nature and in markets}

The aim of this step is to develop an insight into the similitude between the design in nature and engineering design contexts. This is accomplished by exploring the survival requirements of natural systems and engineered products.

\subsubsection{Product design context}

Product designers are required to design in record time, high quality but low cost, environmentally sound products in order to maintain competitiveness in today's markets. There is also the need to address crime issues in the design process. Moreover, products have to adapt to conditions of use/ operation so that they perform reliably their basic function, prevent crime, reduce environmental impact and improve safety. Typically, the design process consists of a series of phases, from market analysis through specifications and concept development to detailed design and production, including use/ operation and end-of-life. These phases have been executed in parallel or concurrently. The core objective is to reduce the time to market, develop solutions that satisfy customer expectations and reduce the development cost. As the coupling of business relationship between manufacturer and customer becomes tighter, it brings about an era of mass customisation driven by the voice and all senses of the customer. A key benefit of increased responsiveness to customer needs is survival. The product concept design is the most important phase of the product design process in order to satisfy customer needs.

\subsubsection{Nature's design context}

Biologists, and more recently engineers, have long researched and understood the evolution of natural systems such as plants and animals. They have explained why there are so many different kinds of living and non-living organisms. They have also explained the process that has created this extraordinary variety of life through millions of years. Moreover, the commonalities among closely related species are also understood now. Extinct species and living species relate in various ways. On the other hand, different kinds of species share so many characteristics of structure and function. Living organisms are notable for their ability to survive through time, in spite of perturbations in their environment. The ability of natural systems to continuously adapt or recreate themselves, while being recognisably the same, is usually known as self-organisation. This ability to maintain identity is related to the fact that these systems have purposes. These purposes provide the framework to sustain their identity. The lack of purpose is usually indicative of the impending collapse of self-organising systems. Natural systems may have many purposes, some of which may not be obvious at all. However, they all share the need to survive. This simply means that they share the aim of continuing to exist, at least until the time when their purpose has been achieved. As this characteristic is shared by all natural systems, it makes sense to focus on this and to examine what elements are necessary in order for an animate or inanimate system to survive and evolve through millions of years. This creative process may provide some insight into the process for conceiving more innovative products.

\subsection{Engineering design and nature's design process}

The aim of this step is to explore in more detail the product design and the process of design in nature in order to investigate the analogy between the two processes. The discussion begins with the 
product design process, emphasising on the concept design phase. Then the theory of evolution, as a design process, is explored.

\subsubsection{The engineering design process}

Traditionally, the design process is segmented into various phases that need to be planned and rigorously controlled (Fig. 2). The formulation of objectives in each phase is of vital importance in any design process. As can be seen in Fig. 2, the design process usually begins with an idea and gradually progresses through details and implementation. The first phase, strategic analysis, is a preliminary step that identifies opportunities, such as market and technology strategic analysis and planning, and long term planning for all the product families. Companies use the strategic planning for expanding their market presence or for developing new capabilities. The emphasis is on the identification of market segments, i.e. which products will be offered to the market, and the development of the product and technology strategy that will guide the whole process.

The second phase, concept design, begins with the specific product project by exploring the market requirements and needs, and the development of new concepts for the new product. Designers develop various concepts for the new product before evaluating and selecting the best concept, which will be engineered and manufactured. The product specifications are defined in the creative step. In order to formulate these specifications, a deep understanding of customer needs, competing products, technological risks, as well as understanding opportunities, the business plan and legal issues is required. The end result of this process includes descriptive parameters that include market segment and the means to satisfy the market needs, product cost, product functions and physical characteristics. Also, it includes technologies that will be integrated into the new design and the required resources to control and manage the design process. The management of the concept design process on the other hand controls and manages the definition process. The main objective of the management process is to trade-off the conflicting aspects such as the product definition, customer requirements, technological constraints, resources and cost.

The third phase, implementation or execution, consists of the following steps: detailed design, development, testing and evaluation of prototypes, manufacturing and logistic activities. The latter includes packaging, transport and distribution, use and end-of-life. The requirements, as identified in the strategic analysis phase and the concept development phase, are transformed into the new product concept. In this phase, the new product concept in the form of technical specifications is transformed into

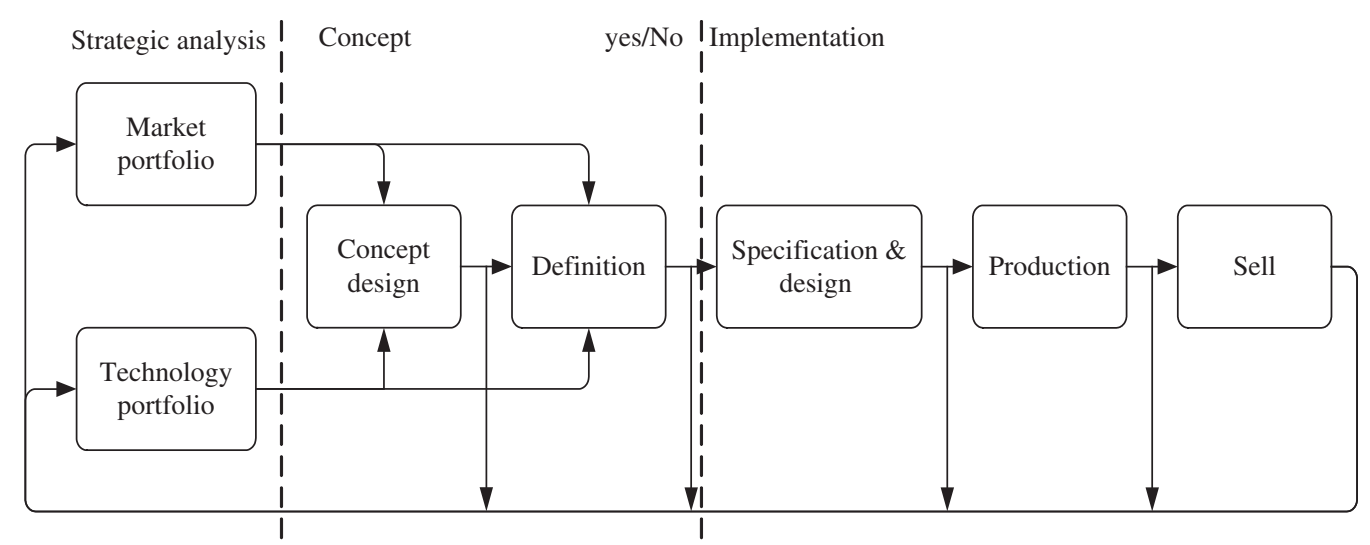

Figure 2: A typical design process. 
functions and attributes for each individual component of the new product so that they can be designed and manufactured individually in downstream stages. One of the aims of the detailed design is to investigate the possible manufacturing processes in order to implement the new concept with its components that will form the total product architecture. The total architecture of the new product not only determines the required components but also the interfaces through which each component interacts with other components. It should be emphasised that the specifications are of vital importance for the design of the total product architecture since they facilitate the design of each component independently and are later integrated into the architecture of the product as a whole. The final result of the detailed design is documents and drawings that describe in detail each component of the new product. This information is used to execute the production and process planning. Before resources are assigned for the manufacturing of the new product, the new design is tested and validated in order to ensure the compliance with the specifications as defined in the previous phases. The tests consist of building prototypes of the new product. The aim is to measure the performance quantitatively and compare this with the expected one. Feasible changes are realised in order to satisfy customer requirements. Once the new design has been tested and validated, the production begins.

\subsubsection{Nature's design process}

According to biologists, evolution accounts for the commonality among living organisms, the diversity of life and many features of the physical world that surrounds us. On the other hand, engineering principles demonstrate that pattern formation and self-organisation are phenomena that occur in both animate and inanimate systems. Evolution is a framework that acknowledges change through time. It focuses on the changes in living organisms during the long history of life on earth. Evolution is the process that has created the extraordinary diversity of life on earth. It accounts for the relatedness among organisms by explaining that species that live on earth are related by descent from common ancestors (Table 1).

The process of designing without designer is a system governed by natural laws. The selforganisation of living beings is the consequence of a natural process called evolution. Organisms adapt to the environment they occupy and their parts adapt to perform certain functions. They are functionally organised. Now, from the perspective of engineering, the phenomenon of generation of design in nature such as shape, structure and geometry can be explained by a single natural law, i.e. constructal law. As mentioned above, this law states that if a system is free to change under global constraints, the architecture of the system changes in time in the direction of flowing more easily. As contrasted in Table 1, the purposeful aspects of living beings are the result of natural laws manifested in natural processes. As a consequence, living beings exhibit design. However, the design of

Table 1: Design without designer as opposed to product design.

\begin{tabular}{ll}
\hline \multicolumn{1}{c}{ Design without designer } & \multicolumn{1}{c}{ Design with designer } \\
\hline - Common descent with modification & $\bullet$ Incremental innovation \\
- Purposeful adaptation or self-organisation & $\bullet$ Purposeful adaptation \\
- Natural selection & $\bullet$ Conscious selection of product features \\
- Organisms evolve through time & $\bullet$ Continuous improvement \\
- Share environment & $\bullet$ Share market segment \\
- Emergent properties & $\bullet$ Emergent properties \\
\hline
\end{tabular}


organisms as they exist, and have existed for millions of years, in nature is not intelligent design. It is the result of the natural process of evolution.

Nature designs animate and inanimate systems with features (variations) that improve their probability of survival and reproduction. In the sense of constructal theory, natural systems change in time in the direction of flowing more easily. It leaves descendants of the same species that have less beneficial variations, i.e. the constructal law asserts itself as less flow access in time. Populations of organisms diverge from their ancestors as differences accumulate over generations. The beneficial traits will increase in frequency over the generations, and less beneficial or harmful variations are eliminated from species. Through a very long period of time, new features will arise. It does not have foresight. It does not anticipate the environments of the future. However, sudden environmental changes may introduce obstacles that may be insuperable to organisms that were previously thriving. Extinction of species is a common outcome of the evolutionary process. On the other hand, a designer has a preconceived plan of what the design will achieve. He/she will select suitable components and materials and arrange them in a preconceived manner in order to fulfil the intended function. Products, as opposed to living organisms, have total appearance of purposefulness because designers conceived their purpose.

\subsection{Evolution as a creative product concept design}

In this section, an attempt is made to generalise the design process of nature into a product concept design process that can be formally expressed and tested. It must be emphasised that the process of testing has already been carried out by biologists and engineers. One can look up the results. These results, such as the evolution and constructal theory, are a scientific model that can be mapped into a product concept design. The mapping has been done through one-to-one transformation, i.e. through an isomorphic transformation, which means roughly similar in pattern. Some detailed explanation of the main characteristics of the biological design process is given first. Then, this understanding is transformed into a product concept design process.

\subsubsection{Evolution as a creative process}

The teleological mechanism of design in nature may be viewed as an attempt to escape from the traditional, mechanistic formulations that now appear inadequate, and to provide new and more fruitful insights and more effective methodologies for generating, evaluating and selecting new product concepts. The self-regulating processes, self-orienting and self-directing features, as accounted for evolution-constructal theory, affect a natural system's form and structure (morphology), function (physiology), behaviour and the interaction with its environment (ecology) (Fig. 3). Designers who are engaged in designing new concepts or reinventing products should pay closer attention to this mechanism. The process of evolution, as a creative process, comes about by the interplay of the random process of mutation and the deterministic process of natural selection. Chance and determinism are an integral part of the evolutionary process. Evolution cannot happen either without mutation or without natural selection.

Mutation or hereditary variation: Slight and dramatic hereditary variations are produced by the process of mutation. In addition to the variations carried over from previous generations, mutation provides each generation of organisms with many new genetic variations. Thus, species are able to adapt to new environmental disturbances. If a variation enables an organism to survive or reproduce more effectively, then that variation would tend to be preserved and spread in a population of organisms through natural selection. The process of mutation that produces the hereditary variations is characterised by chance, i.e. mutations or changes are random events. It is impossible to know which gene will mutate in a particular organism. Moreover, they occur independently of whether or not 


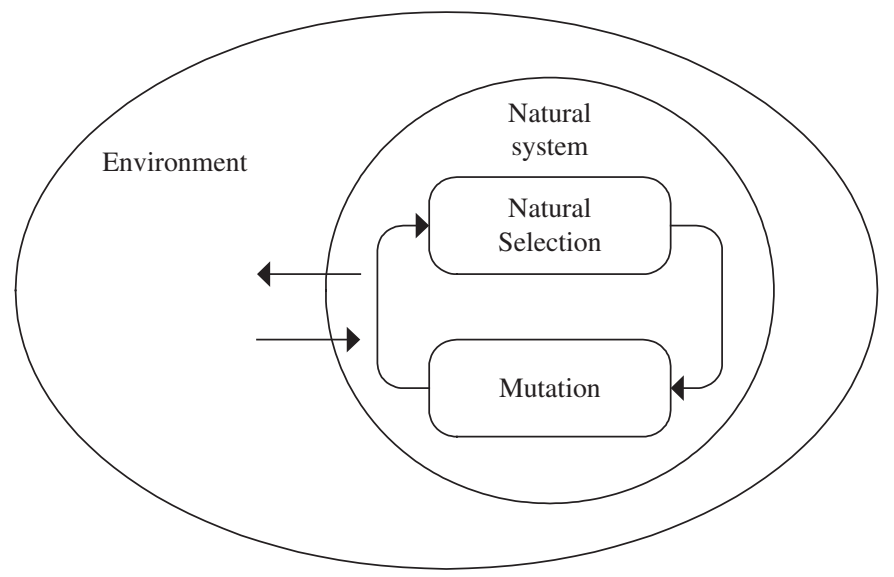

Figure 3: The process of evolution as a creative process.

they are beneficial or harmful to the organism. These changes are not oriented with respect to adaptation. The probabilistic aspect of the mutation process is counteracted by the natural selection, which is a deterministic preservation of what is useful and elimination of what is harmful.

Natural selection: Selection occurs when useful variations increase in frequency and those that are less useful or harmful are eliminated over the generations. Natural systems having useful variations would have better chances of surviving and protecting their species. It is more than a selection process since it generates novelty by increasing the probability of otherwise extremely improbable genetic combinations. Natural selection is primarily an incremental innovation process that operates over time, producing organisms that survive and reproduce better than previous generations. Individuals of a given population of organisms differ from one another at any time only in small ways. These differences typically involve one or a few genes that make the difference between survival and death. For example, the match between background and fur colour protects some animals from predators that are guided largely by vision. Natural selection produces combinations of genes when it comes to complex structures, functions or behaviours. It always favours genes and gene combinations that increase functional effectiveness and proceeds stepwise over long periods of time. Most importantly, the environment, the pre-existing constitution of the organisms and the randomly arising mutations are the key variables determining the direction in which natural selection will proceed.

Evolution also creates new species. According to biologists, the primary source of new species is the process of geographical isolation. Geographical isolation usually forms barriers to the flow of genes. The required isolation is often created by the interposition of a major mountain barrier, the origin of an intermediate desert or changes in the courses of rivers that create reproductive barriers. These barriers allow populations of the same species to diverge from each other through the influence of natural selection. The creation of new species from a pre-existing species requires thousands of years. A human can witness only a small part of this process over his/her lifetime. However, even this small part of evolution in action confirms the theory of evolution as a creative process.

\subsubsection{A creative product concept design}

Figure 4(a) exhibits the one-to-one transformation of the evolution process into a product concept design process. The systemic nature of the process of evolution, i.e. the duality of chance and 


\begin{tabular}{l|lll} 
Evolution : & Mutation & Natural Selection & Environment \\
\hline $\begin{array}{l}\text { Product } \\
\text { Concept }\end{array}$ & $\begin{array}{l}\text { Product } \\
\text { random } \\
\text { Design: }\end{array}$ & $\begin{array}{l}\text { Selection of } \\
\text { useful changes }\end{array}$ & $\begin{array}{l}\text { Adaptation to } \\
\text { market needs }\end{array}$ \\
& & &
\end{tabular}

(a) One-to-one transformation

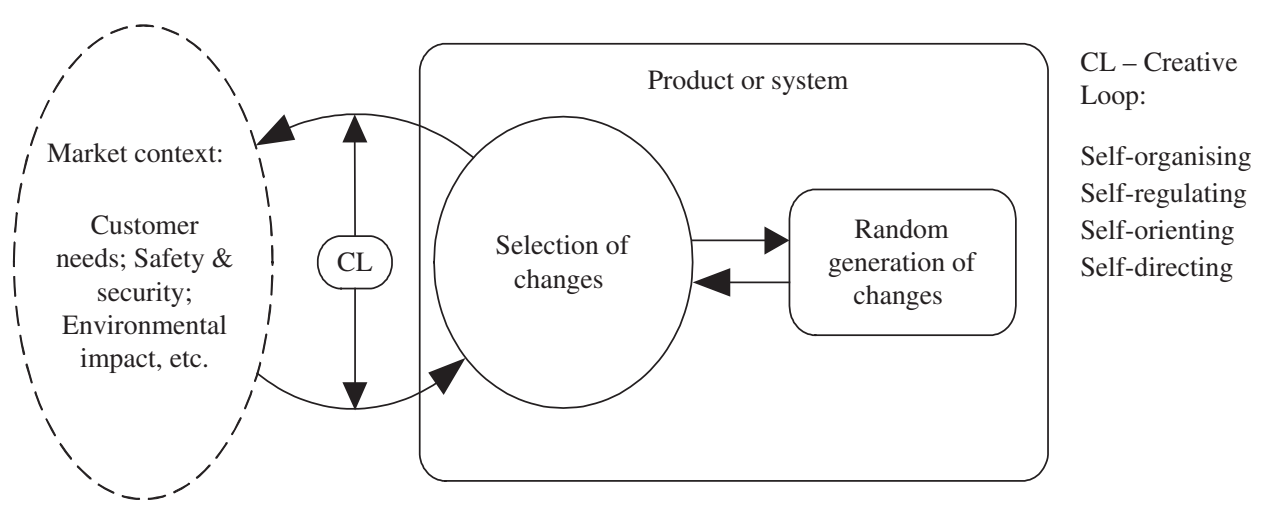

(b) A product concept design model

Figure 4: Mapping the evolution process into a product concept design.

deterministic orientation of order, jointly creates complex and diverse natural systems. Mutation and natural selection jointly drive the creative process. Randomness and determinism are interlocked in a natural process of designing self-organised and self-regulated systems. The direction of the evolution of natural systems is determined by opportunities rather than by necessity. Moreover, it strives to create systems that can adapt to their present environment and not predetermined systems. In this sense, the creative process has some appearance of purposefulness because it is conditioned by the environment. Figure 4(b) depicts the product concept design model resulting from the mapping process.

According to the mapping process, the random generation of variations or changes and the deterministic selection of useful features should drive the creative product concept design. The randomness of the generation process should be counteracted by the selection process, which is a deterministic preservation of features that are useful and elimination of what does not satisfy the market needs. The creative concept design process cannot happen either without the generation of changes or without the selection process. An important characteristic of this process is the preservation of the dynamic equilibrium or balance as represented by the creative loop [Fig. 4(b)]. The instability or imbalance of the loop may lead to undesired situations such as unsatisfied customers, environmental impacts, and safety and security problems.

\section{An illustrative application}

The environment (market): Natural systems, such as trees, are the consequence of complex and long periods of evolution. In order for a tree to survive, it must adapt to its particular environment (Fig. 5). Trees compete in their environment in the process of catching sunlight, absorbing $\mathrm{CO}_{2}$ and growing toward open spaces. They resist effectively the perturbations of the environment such as strong winds, animal damage, pests and droughts. In order to achieve this, they are mechanically strong through the distribution of stresses in their trunks and branches. Trees facilitate the flow of 


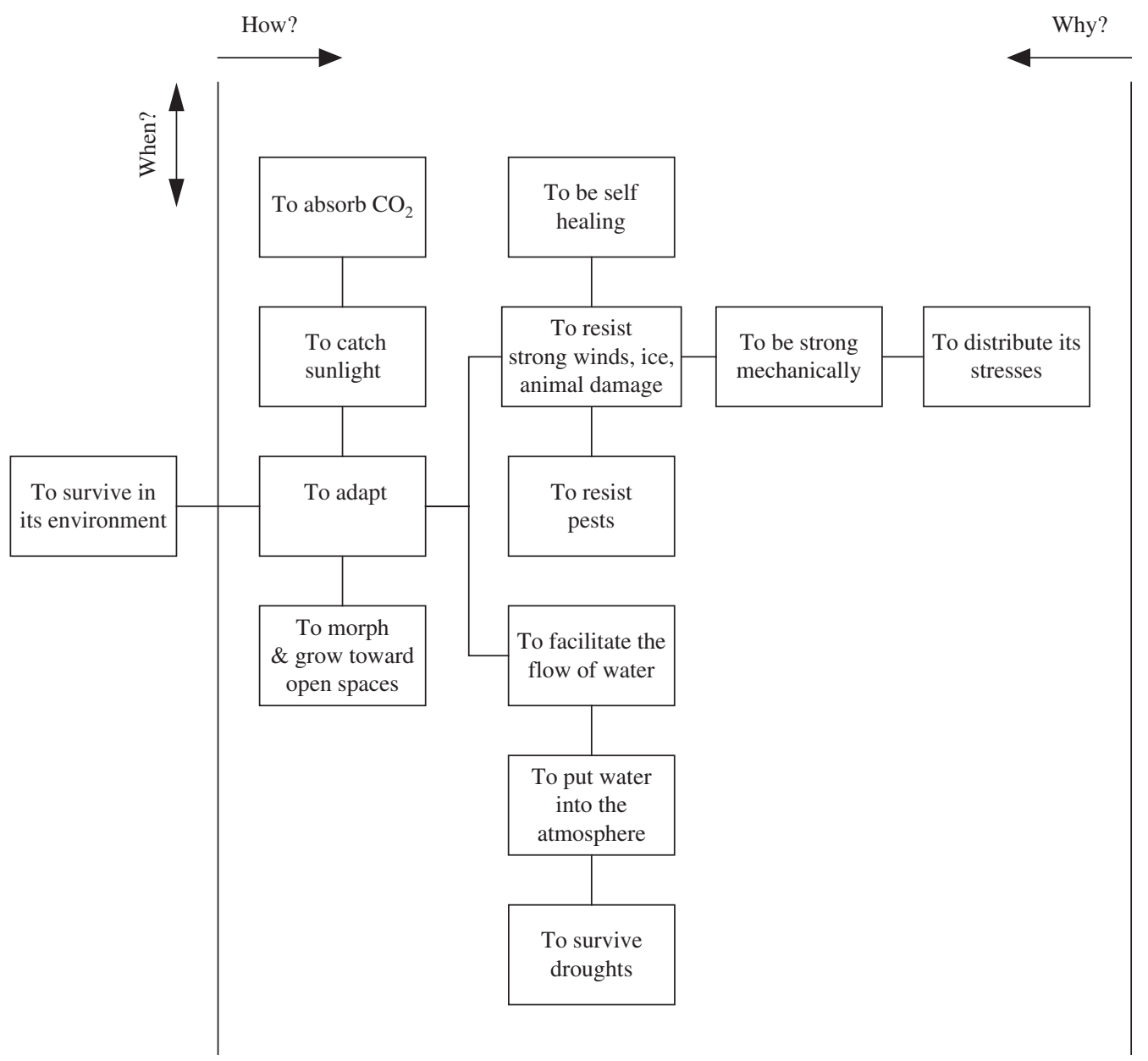

Figure 5: Function analysis system technique diagram for a tree.

nutrients and water from the ground to the atmosphere. They are self-healing systems. Similarly, residential building systems are the consequence of complex and long periods of incremental innovation. Often, these systems evolve from eco-friendly systems to unsustainable habitats. It is common to witness that these systems do not survive the perturbations of the environment such as floods, strong winds, earthquakes and extreme weather conditions. Thus, they do not provide the basic function of protecting occupants from the elements. In order for a building to resist earthquakes, for example, it is made of a rigid and symmetrical structure of reinforced concrete. In poor countries, this has increased the gap between those people that can have access to these systems and those that cannot, i.e. these systems are available only through money. An understanding of the design and functions of natural systems, such as trees, may be of benefit to further innovate the concept of residential building systems in order to comply with the market demands.

Generation of changes: In order to generate changes for the building system, one needs to understand the combined or cooperative effects produced by parts, elements or individuals that constitute the whole system. These interactions impose limitations between the parts. The combination of all parts' 


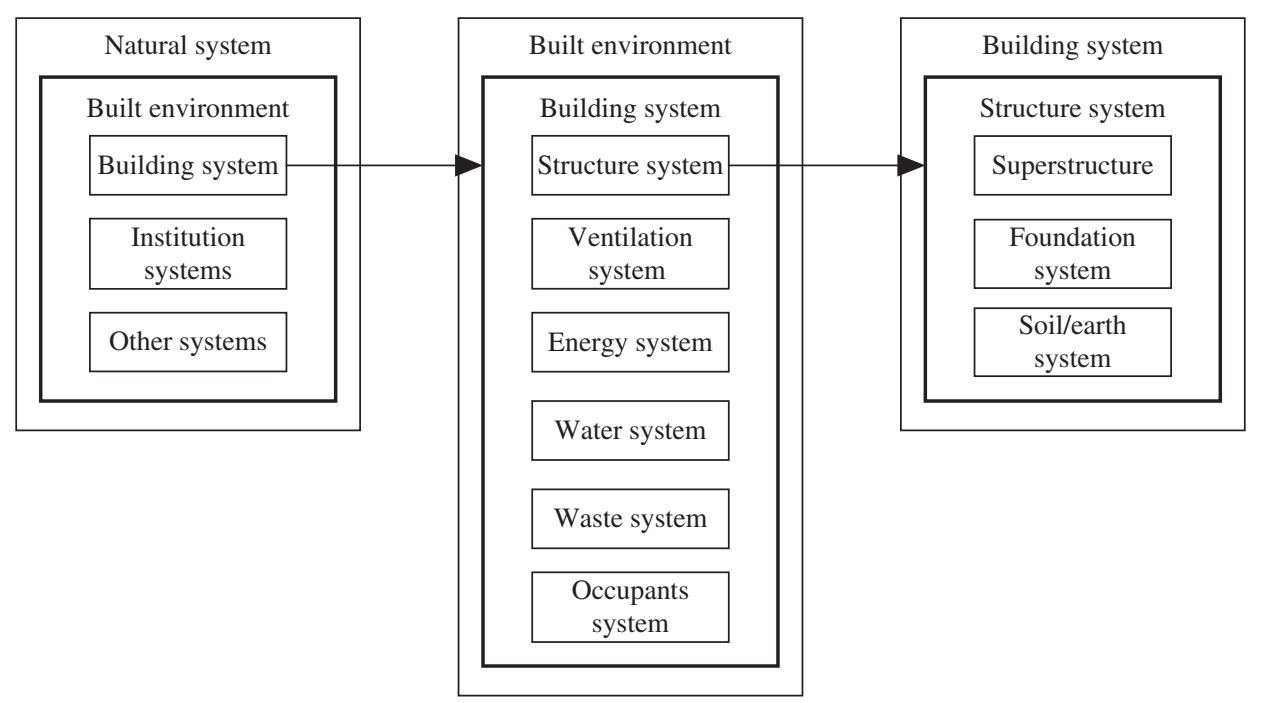

Figure 6: Unfolding the complexity of a building system.

outputs and their interactions complete the total system. Two models namely structural and parametric models have been built in order to generate the changes to the building system. A structural model is a representation of the system's overall structure in recursive levels (Fig. 6). That is, a building system is divided into subsystems so that each subsystem can be analysed and the problem at hand can be solved one part at a time. The structural model depicts three general categories of information. First, it describes a system's composition, i.e. what describes the system's constituents. Second, it describes the system's configuration, i.e. how the constituent components are related to each other. Finally, the important role of a structural model lies in the fact that is the basis for acquiring key product characteristics, which constitute the parametric model (Table 2). There is a fundamental requirement to be met by this set of design parameters, namely, they must be described in plain terms.

Table 2 describes the key characteristics of a typical residential building system. These attributes are the basis for the formulation of the required changes.

According to the structural model (Fig. 6) and the parametric model (Table 2), the structure of the building, just like trees (Fig. 5), must be strong mechanically in order to resist earthquakes, i.e. it must be rigid, flexible and light. In order to achieve this, the foundation of the structure needs some changes. Two steps need to be completed: searching and generating new concepts. The aim of the searching step is to look for existing alternatives in order to develop awareness of existing solutions before developing new ones. Several base isolation technologies, e.g. advanced shock damping devices, rubber steel composite bearings, frictional pendulum systems, hollow spherical balls, etc., can be identified. In general, the main purpose of these technologies is to prevent the structure of the building from absorbing the earthquake's energy. Base isolation technologies are feasible alternatives to conventional earthquake resistant design of medium-rise buildings. However, the wide application of these technologies is still restricted to high life cycle cost.

Generating new concepts is a deliberate process to create new alternatives. In order to achieve this, there should always be a reference or fixed point, i.e. an ideal solution. The architecture of a tree, as described in the section 'The environment (market)', can be used to establish the fixed point. 
Table 2: Parametric model for three subsystems of a typical residential building system.

\begin{tabular}{|c|c|c|c|c|}
\hline \multirow[t]{2}{*}{ System } & \multirow[t]{2}{*}{ Function } & \multicolumn{3}{|c|}{ Changes in the state of the system } \\
\hline & & State of system & Positive effect & Negative effect \\
\hline \multirow[t]{2}{*}{ Structure } & To protect occupants & Rigid and heavy & Resists earthquakes & $\begin{array}{l}\text { Expensive } \\
\text { Inadaptable }\end{array}$ \\
\hline & & Flexible and light & $\begin{array}{l}\text { Less expensive } \\
\text { Adaptable }\end{array}$ & $\begin{array}{l}\text { Damages } \\
\text { Collapses }\end{array}$ \\
\hline \multirow[t]{2}{*}{ Occupants } & To be protected & Rich & Can afford & $\begin{array}{l}\text { Use harmful } \\
\text { materials }\end{array}$ \\
\hline & & Poor & $\begin{array}{l}\text { Use more natural } \\
\text { materials }\end{array}$ & Cannot afford \\
\hline \multirow[t]{2}{*}{ Soil/earth } & To support structure & Does not move & Does not damage & \\
\hline & & Does move & & $\begin{array}{l}\text { Damages } \\
\text { Collapses } \\
\text { structure }\end{array}$ \\
\hline
\end{tabular}

A tree is a machine that resists extreme weather conditions, such as strong winds, including earthquakes. Thus, the ideal solution for the building system is that the structure must adapt itself to the motion of the earth while retaining its main function of protecting the occupants. Figure 7 shows a schematic representation of this concept. There is no new element in the foundation of the structure.

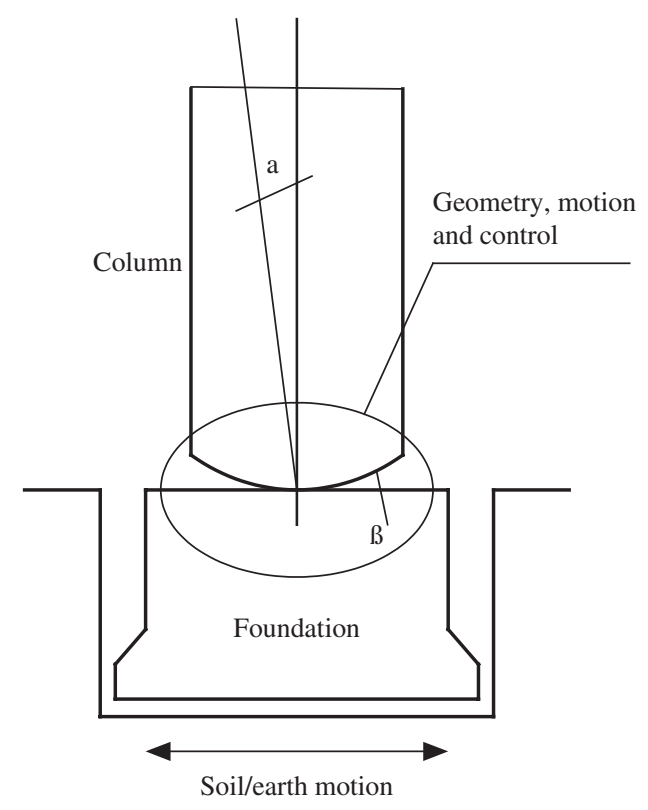

Figure 7: The ideal concept for the structure of a building system in order to resist earthquakes. 
Instead, the interaction of the column and the foundation is modified through a geometric change in order to control the motion of the whole building structure.

Selection: In the selection phase of the approach, the aim is to evaluate and select the best concept. It consists of three main steps. First, screening concepts can be used to reduce the large number of alternatives to a few feasible ones. The aim is to eliminate concepts that are not feasible according to the fixed point, i.e. the chosen natural system. Regarding the building system, the existing concepts identified in the searching step were eliminated because of the high cost and the complexity of the technology transfer. Second, concepts can be further evaluated and eliminated. Several modes of evaluation can be exercised here. An individual can make a choice based on his/her own criteria or procedure. A team of designers with conflicting goals can evaluate and choose a concept, based on an established procedure and criteria. Also, a more rigorous factual evaluation can be carried out in order to select a concept that is closer to the ideal one. The authors' judgment has been used to select the concept of the structure shown in Fig. 7. Finally, a complete concept solution can be reached after completing the evaluation step. The aim is to accept or reject the selected concept. The next logical step is to detail design the accepted concept.

\section{CONCLUSIONS AND FURTHER RESEARCH}

This paper describes a process of design in nature in order to develop an understanding that may be of benefit in product conceptual design. It maps the evolutionary design process into the traditional product conceptual design process, resulting in a creative process for product concept design. It is hoped that this insight may help designers gain further understanding of product concepts' generation, evaluation and selection. This bridging effort can turn nature's invention process into engineering design capabilities. There are many characteristics of animate and inanimate systems, such as the capability to operate autonomously in complex environments, being able to adapt to unplanned and unpredictable changes and perform various functions. This may help to conceive such concepts that can dramatically increase the capabilities or even superior to natural systems. This approach is a conceptual model that requires further refinements and to be validated with case studies and practical applications, such as control and reliability and safety and security engineering.

\section{ACKNOWLEDGEMENTS}

Thanks are extended to the two anonymous reviewers for their valuable comments in order to update and strengthen this paper.

\section{REFERENCES}

[1] National Academy Press, Improving engineering design: design for competitive advantage, http://books.nap.edu/catalog/1774.html.

[2] National Academy Press, Approaches to improving engineering design, http://books.nap.edu/ catalog/10502.html.

[3] Santos-Reyes, D.E. \& Lawlor-Wright, T., A design for the environment methodology to support and environmental management system. Integrated Manufacturing Systems, 12(5), pp. 323-332, 2001. doi:10.1108/EUM0000000005710

[4] Huisman, L., Boks, C.B. \& Stevels, A.L.N., Quotes for environmentally weighted recyclability (QWERTY): concept of describing product recyclability in terms of environmental value, Int. J. Prod. Res., 41(16), pp. 3649-3665, 2003. doi:10.1080/0020754031000120069

[5] Nahm, E.Y. \& Ishikawa, H., Integrated product and process modelling for collaborative design environment, Concurrent Engineering: Research and Applications, 12(1), pp. 5-23, 2004. 
[6] Hauser, J.R. \& Clausing, D., The house of quality, Harvard Business Review, May-June, pp. 63-73, 1988.

[7] Nagamachi, M., Kansei engineering: a new ergonomic consumer-oriented technology for product development, International Journal of Industrial Ergonomics, 15, pp. 3-11, 1995. doi:10.1016/0169-8141(94)00052-5

[8] Pugh, S., Total Design: Integrated Methods for Successful Product Engineering, AddisonWesley Publishing Company: Wokingham, 1995.

[9] Yeo, S.H., Mak, M.W. \& Balon, S.A.P., Analysis of decision-making methodologies for desirability score of concept design, Journal of Engineering Design, 15(2), pp. 195-208, 2004. doi:10.1080/09544820310001642191

[10] Altshuller, G., Creativity As an Exact Science, Gordon and Breach Publisher: The Netherlands, 1984.

[11] Alting, L., Designing for a life time, Manufacturing breakthrough, May/June, pp. 323-332, 1993.

[12] Smith, M.J. \& Tilley, N. (eds.), Crime Science: New Approaches to Preventing and Detecting Crime, Willan Publishing: Cullompton, 2005.

[13] Santos-Reyes, D. \& Santos-Reyes, J., Patterns and rates of crime evolution in Mexico, Safety and Security Engineering II, ed. M. Guarascio, Wit Press: Southampton, pp. 119-127, 2007.

[14] Santos-Reyes, D., Biological insight into design against crime, Design and Nature IV, ed. C.A. Brebbia, WIT Press: Southampton, pp. 43-50, 2008.

[15] Armitage, R. \& Pease, K., Design and crime: proofing electronic products and services against theft, European Journal on Criminal Policy and Research, 14, pp. 1-9, 2008. doi:10.1007/ s10610-007-9043-6

[16] Vogel, S., Cat's Paws and Catapults: Mechanical Worlds of Nature and People, Norton: New York, 1998.

[17] Benyus, J.M., Biomimicry Innovation Inspired by Nature, Harper-Collins Publishers: New York, 1997.

[18] Bejan, A., Shape and Structure, from Engineering to Nature, Cambridge University Press: Cambridge, UK, 2000.

[19] Reis, A.H., Miguel, A.F. \& Bejan, A., Constructal theory of particle agglomeration and design of air-cleaning devices, J.Phys. D. Appl. Phys., 39, pp. 2311-2318, 2006. doi:10.1088/00223727/39/10/046

[20] Von Stamm, B., About: Innovation, Design Council, http://www.designcouncil.org.uk.

[21] Osborn, A., Applied imagination, Scribner: New York, 1979.

[22] Zwicky, P., Discovery, Invention, Research Through Morphological Analysis, McMillan: New York, 1969.

[23] Gordon, W.J., Synectics, the Development of Creative Capacity, Harper: New York, 1961.

[24] Liu, Y.C., Blight, T. \& Chakrabarti, A., Towards an ideal approach for concept generation, Design Studies, 24, pp. 341-355, 2003. doi:10.1016/S0142-694X(03)00003-6

[25] Stone, R.B., Rolla, M.R., McAdams, D.A. \& Kayyalethekkel, V.J., A product architecturalbased conceptual DFA technique, Design Studies, 25, pp.301-325, 2004. doi:10.1016/j. destud.2003.09.001

[26] Shah, J.M., Vargas-Hernandez, N. \& Smith, S.M., Metrics for measuring ideation effectiveness, Design Studies, 24, pp. 111-134, 2003. doi:10.1016/S0142-694X(02)00034-0

[27] Zheng, J.M., Chan, K.W. \& Gobson, I., Desktop virtual reality interface for computer aided conceptual design using geometric techniques, Journal of Engineering Design, 12(4), pp. 309-329, 2001. doi:10.1080/09544820110085931 
[28] Ottosson, S., Virtual reality in the product development process, Journal of Engineering Design, 13(2), pp. 159-172, 2002. doi:10.1080/09544820210129823

[29] Azariadis, P.N. \& Sapidis, N.S., Drawing curves onto a cloud of points for point-based modeling, Computer-Aided Design, 37, pp. 109-122, 2005. doi:10.1016/j.cad.2004.05.004

[30] Choi, S.H. \& Cheung, H.H, A multi-material virtual prototyping system, Computer-Aided Design, 37, pp. 123-136, 2005. doi:10.1016/j.cad.2004.06.002

[31] Yang, Z. \& Chen, Y., A reverse engineering method based on haptic volume removing, Computer-Aided Design, 37, pp. 45-54, 2005. doi:10.1016/j.cad.2004.03.003

[32] Gelsey, A., Schwabacher, M. \& Smith, D., Using modeling knowledge to guide design space search, Artificial Intelligence, 101, pp. 35-62, 1998. doi:10.1016/S0004-3702(98)00012-5

[33] Li, X. \& Schmidt, L., Grammar-based designer assistance tool for epicyclic gear trains, Journal of Mechanical Design, 126, pp. 895-902, 2004. doi:10.1115/1.1767823

[34] Tovey, M. \& Porter, S., Sketching, concept development and automotive design, Design Studies, 24, pp. 135-153, 2003. doi:10.1016/S0142-694X(02)00035-2

[35] Simon, H.A., Discovery, invention and development: human creative thinking, Proceedings of the National Academy of Science, 80, pp. 4569-4571, 1983. doi:10.1073/pnas.80.14.4569

[36] Barker, G. \& Bissell, P., About: Invention, Design Council, http://www.designcouncil.org.uk.

[37] Sarett, L.H., Research and invention, Proceedings of the National Academy of Science, 80, pp. 4572-4572, 1983. doi:10.1073/pnas.80.14.4572

[38] Cavdar, K. \& Babalik, F.C., Creativity effect with computer program for product designers, Journal of Engineering Design, 15(3), pp. 249-260, 2004. doi:10.1080/09544820410001676166

[39] Redelinghuys, C., Proposed measures for invention gain in engineering design, Journal of Engineering Design, 11(3), pp. 245-263, 2000. doi:10.1080/095448200750021012

[40] Kim, Y.-S. \& Cochran, D.S., Reviewing TRIZ from the perspective of axiomatic design, Journal of Engineering Design, 11(1), pp. 79-94, 2000. doi:10.1080/095448200261199

[41] Suh, N.P., The principles of design, Oxford University Press: New York, 1990.

[42] Stefik, M. \& Smoliar, S., The creative mind: myths ad mechanisms: six reviews and a response, Artificial Intelligence, 79, pp. 65-67, 1995. doi:10.1016/0004-3702(95)00067-4

[43] Ulmasov, K.A., Shammakov, S., Karaev, K. \& Evgen'ev, M.B., Heat shock proteins and thermoresistance in lizards, Proc. Natl. Acad. Sci., 89, pp. 1666-1670, 1992. doi:10.1073/ pnas.89.5.1666

[44] Perales, H.R., Benz, B.F. \& Brush, S.B., Maize diversity and ethnolinguistic diversity in Chiapas, Mexico, Proc. Natl. Acad. Sci., 102(3), pp. 949-954, 2005. doi:10.1073/pnas.0408701102

[45] Mares, M.A., South American mammal zoogeography: evidence from convergent evolution in desert rodents, Proc. Natl. Acad. Sci., 72(5), pp. 1702-1706, 1975. doi:10.1073/pnas.72.5.1702

[46] Sol, D., Duncan, R.P., Blackburn, T.M., Cassey, P. \& Lefebvre, L., Big brains, enhanced cognition, and response of birds to novel environments, Proc. Natl. Acad. Sci., 102(15), pp. 5460-5465, 2005. doi:10.1073/pnas.0408145102

[47] De Moraes, C.M. and Mescher, M.C., Biochemical crypsis in the avoidance of natural enemies by an insect herbivore, Proc. Natl. Acad. Sci., 101(24), pp. 8993-8997, 2004. doi:10.1073/ pnas.0403248101

[48] Avise, J.C. \& Ayala, F.J., In the light of evolution I: adaptation and complex design, Proc. Natl. Acad. Sci., 104(1), pp. 8563-8566, 2007. doi:10.1073/pnas.0702066104

[49] Bejan, A., Shape and Structure, from Engineering to Nature, Cambridge University Press: Cambridge, UK, 2000.

[50] Bejan, A. \& Lorente, S., Constructal theory of generation of configuration in nature and engineering, J. Appl. Phys., 100, 041301, 2006. doi:10.1063/1.2221896 
[51] Bejan, A., Advanced Engineering Thermodynamics, Second edn, Wiley: New York, 1997.

[52] Bejan, A., Advanced Engineering Thermodynamics, Third edn, Wiley: Hoboken, 2006.

[53] Ciobanasm, A., Bejan, A. \& Fautrelle, Y., Dentritic solidification morphology viewed from the perspective of constructal theory, J. Phys. D. Appl. Phys., 39, pp. 5252-5266, 2006. doi:10.1088/0022-3727/39/24/023

[54] Miguel, A.F., Constructal pattern formation in stony corals, bacterial colonies and plant roots under different hydrodynamics conditions, J. Theor. Biol., 242, pp. 954-961, 2006. doi:10.1016/j.jtbi.2006.05.010

[55] Biondini, M., Allometric scaling laws for water uptake by plant roots, J. Theor. Biol., 251, pp. 35-59, 2008. doi:10.1016/j.jtbi.2007.11.018

[56] Reis, A.H., Miguel, A.F. \& Aydin, M., Constructal theory of flow architecture of the lungs, Med. Phys., 31, pp. 1135-1140, 2004. doi:10.1118/1.1705443

[57] Reis, A.H., Constructal view of scaling laws of river basins, Geomorphology, 78, pp. 201-206, 2006. doi:10.1016/j.geomorph.2006.01.015

[58] Bejan, A. \& Marden, J.H., Unifying constructal theory for scale effects in running, swimming and flying, J. Exp. Biol., 209, pp. 238-248, 2006. doi:10.1242/jeb.01974 